\title{
East Asian Monsoon Signals Recorded in the Japan Sea Sediments
}

Tomohisa Irino1, Ken Ikehara 2, Hajime Katayama3, Yugo 0n04, Ryuji Tada 5

1 Graduate School of Environmental Earth Science, Hokkaido University, Sapporo, Japan. irino@ees.hokudai.ac.jp

2 Institute of Marine Resources and Environment, National Institute of Advanced Industrial Science and Technology, Tsukuba, Japan.

k-ikehara@aist.go.jp

3 Institute of Marine Resources and Environment, National Institute of Advanced Industrial Science and Technology, Tsukuba, Japan. katayama-h@aist.go.jp

4 Graduate School of Environmental Earth Science, Hokkaido University, Japan. yugo@ees.hokudai.ac.jp

5 Department of Earth and Planetary Sciences, University of Tokyo, Tokyo, Japan. ryuji@eps.s.u-tokyo.ac.jp

East Asia is the region where the warm-humid summer southeast monsoon and the cold-dry winter northwest monsoon meet. Both monsoons are subsystems of the large-scale heat and moisture exchange between northern and southern hemisphere (An, 2000). Because marginal seas located at the eastern edge of Asian Continent record both monsoon variations as well as how oceanic circulation and ecosystems have responded to these climatic variations, they are key archives in the PAGES-PEP ॥ transect.

\section{Variations in the East Asian Monsoon}

The Japan Sea is a semi-enclosed marginal sea located between the eastern margin of the Asian Continent and Japan. Because of its semi-enclosed nature, the Japan Sea has responded sensitively to variations in the East Asian monsoon and related oceanographic changes. The sediments in water deeper than 800 $\mathrm{m}$ are characterized by alternating centimeter to decimeter scale of dark and light colored layers (Figure 1). These layers can be correlated widely within the Japan Sea (Tada et al., 1992). The occurrence of dark layers is associated with interstadial periods in Dansgaard-Oeschger (D-O) cycles except for the one corresponding to LGM that was formed under stratified conditions due to isolation of the Japan sea and consequent decrease in the surface water salinity (Dansgaard et al., 1993; Tada et al., 1999). Dark layers during oxygen isotope stages 3-5 are characterized by 1) higher organic carbon content, 2) diatom assemblages indicating lower salinity surface water, and 3) pollen assemblages showing relatively warmer, wetter conditions compared to light layers (Tada et al., 1999; Ikehara et al., 1994). These multiple lines of evidence suggest that stronger summer monsoon precipitation in East Asia resulted in a higher supply of fresh water and nutrients from land to coastal water in the East China Sea. This would lead to lower salinity and higher primary productivity in the surface water of the Japan Sea and dark layer sediments with higher organic carbon content. Freshwater would also result in weakened ventilation of the deep water, thereby enhancing organic carbon preservation during dark layer deposition.

Therefore, these record suggest that the East Asian summer monsoon precipitation varied in association with D-O cycles.

\section{A Possible Extreme Cooling Event}

Japan Sea sediments have also recorded another kind of paleoceanographic variation. In a sediment core from St. 1246 taken during the GH99 cruise held by the Geological Survey of Japan in summer 1999 (Figure 1), we find not only the dark-light cycles described above but also frequent intercalation of thin $(<1 \mathrm{~cm})$ pale green layers. These pale green layers occur frequently within both dark and light layers in the interval between oxygen isotope stage 3 and late stage 5 . They often contain gravel which was likely to have been transported by sea ice. In the deeper part of the Japan Sea, pale green layers frequently occurred during glacial times. At intermediate depths, their formation was less frequent during stage 3 . In the shallow waters, no pale green layer formation occurred. These facts suggest that the for-

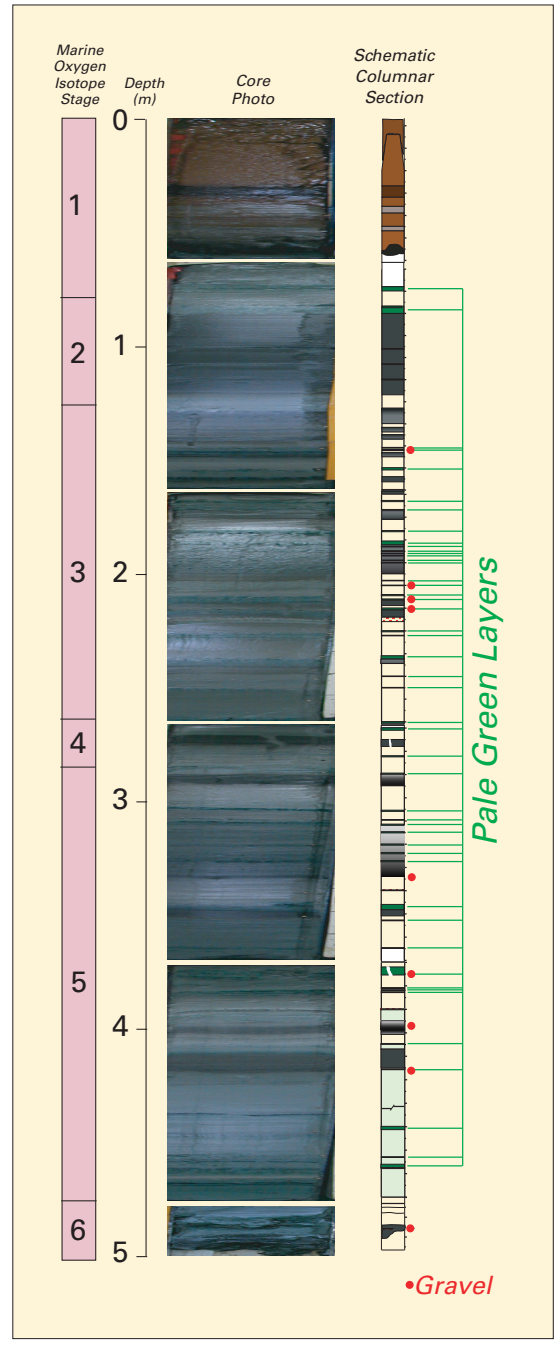

Fig. 1. Appearance of typical Japan Sea sediment core (GH99-St. 1246). Horizons of pale green layers and gravel occurrence are shown. Approximate positions of marine oxygen isotope boundaries are also shown using the age model established by Tada et al. (1999).

mation of these pale green layers could be related to centennial-scale events associated with the variation in bottom water circulation and the sea ice expansion during the glacial period, which occurred during both stadials and interstadials. These events may have been related to changes in the winter monsoon circulation, and show no significant correlation with D-O cycles. 


\section{Science Highlights}

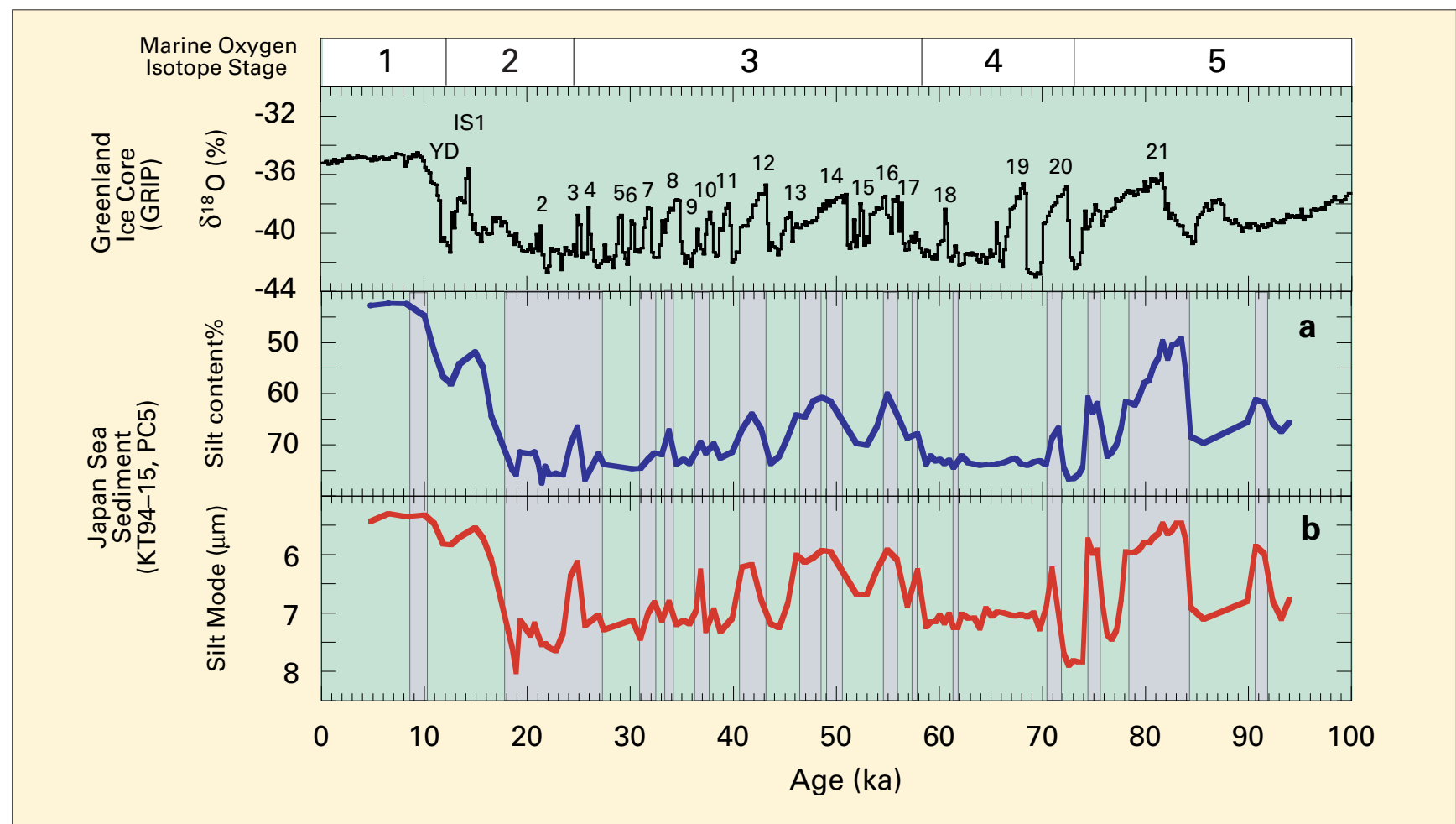

Fig. 2. Temporal variations of aeolian dust (silt) content (a) and grain size (b) in core KT94-15-PC5 recovered from the Japan Sea. The gray area indicates the position of dark layers. Oxygen isotope variations from GRIP ice core are also shown for comparison .

\section{Variations in Aeolian Dust}

Japan Sea sediments also recorded variations in aeolian dust supply because of the Sea is located just downwind the arid Central Asian dust source area (Irino and Tada, 2000). We have analyzed chemical and mineral composition of hemipelagic sediments from selected locations. Our results show that the sediments consist of two detrital subcomponents, which are attributed to aeolian dust and detrital materials derived from the Japan Arc, respectively. Further evaluation of detrital grain size distribution and chemical composition of the KT9415-PC5 sediment core reveals that the silt size fraction $(\sim 6 \mu \mathrm{m})$ within Japan Sea sediments consists almost entirely of aeolian dust and the clay size fraction $(\sim 3.5 \mu \mathrm{m})$ consists primary of Japan Arc derived detritus (Tada et al., 2000). Temporal variation of aeolian dust (silt) content in the Japan Sea sediments shows millennial scale fluctuations coincident with dark-light cycles (D-O cycles). Silt content is lower during the dark layer deposition except during the LGM (Figure 2a). This fact suggests that a humidarid cycle associated with summer monsoon variability in East to Cen- tral Asia resulted in variations in dust availability from Central Asia and/or riverine supply from the Japan Arc. Aeolian dust (silt) grain size also shows temporal variations associated with D-O cycles, with grain size being smaller during dark layer deposition except at the LGM (Figure 2b). Both silt content and mode indicate an intensification of dust supply around the LGM. Such dust can be transported by winter monsoon winds and westerlies (Ono et al, 1998). Our results therefore suggest that the winter monsoon and westerlies vary in harmony with D-O cycles.

\section{Do the winter and summer monsoons vary independently?} Recent progress in paleoceanographic and paleoclimatic reconstructions provide consistent evidence that summer monsoon precipitation in East Asia varies with D-O cycles. In the case of winter monsoon, a discrepancy between fluctuation patterns of some proxies such as sea ice extent and aeolian dust grain size is recognized. Porter and An (1995) showed that magnetic susceptibility, a summer monsoon indicator in loess sequences, has a different pattern of fluctuation than quartz grain size (a winter monsoon indicator). It is not clear if this discrepancy is of a hemispheric scale significance or represents a local response of the Japan Sea. In order to solve such problems, it is necessary to compare multiproxy, independent summer and winter monsoon signals derived both from terrestrial and oceanic records.

Understanding linkages between the East Asian monsoon and weterlies is another important topic to be addressed in the context of the PEP II transect.

\section{REFERENCES}

An, Z., 2000, Quaternary Science Reviews, 19, 171-187.

Dansgaard, W. et al., 1993, Nature, 364, 218-220. Ikehara, K. et al., 1994, Proc. 29th IGC, Part B, VSP, 229-235.

Irino, T. and Tada, R., 2000, Geochemical Journal, 34, 59-93.

Ono,Y et al., 1998, Global and Planetary Changes, 18,129-135.

Porter, S. C. and An, Z., 1995, Nature, 375, 305-308 Tada, R. et al., 1992, Proc. ODP Scientific Results, 127/128, 577-522.

Tada, R. et al., 1999, Paleoceanography 14, 236-247.

For full references please consult:

www.pages-igbp.org/products/newsletter/ref20012.html 